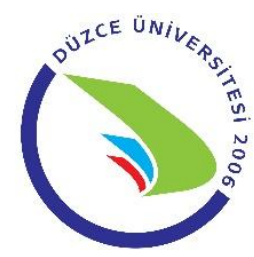

\title{
COVID-19 Pandemisinin Sağlık Programlarında Öğrenim Gören Öğrencilerde Belirsizliğe Tahammülsüzlüğe Etkisi
}

\author{
Betül ÖNAL 國, Aysun KAZAK ${ }^{2}{ }^{2}$, Serdar KARAKULLUKÇU ${ }^{3}{ }^{3}$ Ersin ÖNAL ${ }^{4}$
}

\section{ÖZ}

Amaç: $\mathrm{Bu}$ araştırma, COVID-19 pandemisinin sağlık programlarında öğrenim gören öğrencilerde belirsizliğe tahammülsüzlüğe etkisini belirlemek amacıyla yapılmıştır.

Gereç ve Yöntemler: Tanımlayıcı olarak planlanan araştırmanın evrenini Karadeniz bölgesinde bulunan iki devlet üniversitesinin meslek yüksekokulunda öğrenim gören sağlık bölümü (diyaliz, ilk ve acil yardım, fizyoterapi, yaşlı bakımı, çocuk gelişimi, tıbbi laboratuvar teknikleri, tıbbi dokümantasyon ve sekreterlik) 2. sınıf öğrencileri oluşturmuş olup çalışmaya katılmayı kabul eden 807 öğrenci örneklemi oluşturmuştur. Veriler Mayıs 2020 de birey tanıtım formu, belirsizliğe tahammülsüzlük ölçeği kullanılarak toplanmıştır. Verilerin istatistiksel analizinde; sayı, yüzde, ortalama ile verilmiş, karşılaştırmalarda Student-t test ve ki-kare testi kullanılmıştır.

Bulgular: Araştırmaya katılan öğrencilerin \%76,6'si kadın, \%70,8'inin gelir durumu orta düzeyde, \%47'sinin il merkezinde yaşadığı belirlenmiştir. Öğrencilerin \%95,2 sosyal izolasyon önlemi almışken \%18,3 kendisi veya yakınları karantinaya alınmıştır. Öğrencilerin pandemi döneminde ruh hali değişimi incelendiğinde \%53,7'sinin kötüye gittiği, \%63,2'sinin psikososyal destek hizmeti aldığı belirlenmiștir. Öğrencilerin COVID - 19'a ilişsin verileri ile belirsizliğe tahammülsüzlük ölçeğinden alınan puanlar karşılaştıııldığında, ruh hali değişimini kötü olarak niteleyenlerde, karantinaya alınanlarda, psikososyal destek hizmeti alanlarda ölçek puanlarında istatistiksel olarak farkın önemli olduğu belirlenmiștir $(\mathrm{p}<0,05)$.

Sonuç: Pandemi döneminde öğrenciler sosyal izolasyona dikkat etmiş, pandemi öğrencilerin ruh halini olumsuz yönde etkilemiş̧tir. Geleceğin sağlık profesyonelleri öğrencilerimizin standart sağlık eğitiminin bir parçası olarak psikososyal destekli eğitimin etkisinin duyarlılık programlarıyla farkındalık kazandırılması gereklidir.

Anahtar Kelimeler: COVID-19; pandemi; öğrenci; belirsizlik.

\section{The Effect of COVID-19 Pandemic on the Intolerance of Uncertainty of Students Studying in Health Departments}

\section{ABSTRACT}

Aim: The study examines to determine the effect of COVID-19 pandemic on uncertainty and intolerance of students studying in health programs.

Material and Methods: The population of the research, which is planned as a descriptive, is consisted of second-year students in the department of health studying at the regional vocational school of the two state universities in the Black Sea region and 807 students who have agreed to participate in the study sample. In the statistical analysis of data, the dual comparison of the number, percentage, average is performed with Student T test and Ki Square test.

Results: It has been determined that $76.6 \%$ of the students participating in the study are women, $70.8 \%$ of them have a moderate-income level, $47 \%$ of them live in the city center. While $95.2 \%$ of the students took social isolation measures, $18.3 \%$ of them or their relatives were quarantined. When the mental health change of the students were questioned during the pandemic period, it was determined that $53.7 \%$ of them got worse and $63.2 \%$ of them received psychosocial healthcare. When the data of the students regarding COVID-19 and the scores obtained from the scale of intolerance of

\footnotetext{
1 Yozgat Bozok Üniversitesi Akdağmadeni Sağlık Yüksekokulu, Hemşirelik Bölümü, Yozgat, Türkiye

2 Mersin Üniversitesi Sağlık Hizmetleri Meslek Yüksekokulu Tıbbi Hizmetler ve Teknikler Bölümü Illk ve Acil Yardım Programı, Mersin, Türkiye

3 Rize İ Sağlık Müdürlüğü, Rize, Türkiye

4 Bayburt Akşar 14 nolu Aile Hekimliği, Bayburt, Türkiye
}

Sorumlu Yazar / Corresponding Author: Aysun KAZAK, e-mail: aysn1108@gmail.com

Geliş Tarihi / Received: 09.06.2020, Kabul Tarihi / Accepted: 06.11.2021 
uncertainty were compared, the scale scores were found to be statistically significant in those who considered mental health change as bad, quarantined, psychosocial healthcare received $(\mathrm{p}<0.05)$.

Conclusion: During the pandemic period, students are highly socially isolated, pandemic affected students psychology in a negative way. The future professionals of our healthcare system, need to raise awareness for education based on psychosocial health through sensitivity programs as a part of the standard healthcare education.

Keywords: COVID-19; pandemic; student; uncertainty.

\section{GIRIS}

Çin'in Hubei eyaletinin Wuhan şehrinde Aralık 2019'da ortaya çıkan ve kısa zamanda tüm Dünyaya yayılarak "pandemi"ye sebep olan COVID-19, çok acil ve ciddi bir halk sağlığı problemidir. Bir yandan bu hastalığa yakalanan hastaların mücadelesi diğer yandan bu virüsün yayılımının önüne geçebilmek için çabalar sürmektedir. Yapılan bilimsel çalışmalar sonucunda veriler her saat başı güncellenmekte ve güncellenen bu veriler doğrultusunda sağlık çalışanları ve toplum kendini devamlı yenilemek zorunda kalmaktadır. Bu zamana kadar virüse karşı geliştirilmiş kanıt düzeyli bir aşı veya tedavi bulunmamaktadır. Hastalıktan korunmanın en etkin yolu virüse maruz kalmamaktır (1). Bu hastalık için önerilen etkin yöntemler hijyen, sosyal izolasyon ve temastan kaçınmaktır $(2,3)$.

Sosyal izolasyonu sağlamak amaciyla bir dizi önlemler alınmıştır. Ülkemizde de uygulanan iş yerlerinde dönüşümlü veya uzaktan çalışma yöntemleri, toplantıların ertelenmesi, tiyatro, sinema, alışveriş merkezi gibi insan yoğunluğunun fazla olduğu yerlerin kapatılması ve çocukların erişkinlere bulaştırma ihtimali bulunduğundan okulların kapatılması hem etkili hem de kanıta dayalı önlemlerdir (3). Her ne kadar bu önlemler ve çabalar son derece gerekli olsa da beraberinde endişelere sebep olmaktadır. Çünkü bir hastalık salgını sırasında uzun süreli okul kapanması ve ev hapsi ögrencilerin fiziksel ve zihinsel sağlığı üzerinde olumsuz etkilere neden olabilir (4). Araştırmalar, öğrencilerin okula gitmediği zamanlarda (hafta sonları ve yaz tatilleri) fiziksel olarak daha az aktif olduklarını, daha uzun süre ekran başında vakit geçirdiklerini, uyku düzenlerinin bozulduğu ve uygunsuz diyetlere sahip olduklarını, bunun da kilo alımı ve kardiyovasküler hastalıklarla sonuçlandığını göstermektedir (5). Pandemi sürecinde üniversite öğrencileriyle yapılmış çalışmalarda psiko-duygusal sıkıntıların öğrenciler üzerinde büyük bir etkiye sahip olduğu belirtilmektedir (6-10). Pandemi süreci ile ilişkili öngürülemezlik ve değişkenlik göz önüne alındığında, COVID-19 belirsizliğe tahammülsüzlüğü yüksek olan kişiler için özellikle zorlu bir süreç olabilir (11).

Belirsizlik; belirsizlik ve etkileri konusunda olumsuz inançların sonucunda ortaya çıkan ruhsal karakteristik bir hoşgörüsüzlüktür (12). Belirsizlik hem özgüven duygusunu zedeler hem de insanların toplumda pasif ve istikrarsız kalmasına yol açar. Ayrıca insanların karar verme yetilerini en aza indirir ve bu durum insanın ruhsal olarak bazı bozukluklar yaşamasına neden olur (13). Belirsizliğe tahammülsüz kişilerin karar alma sürecinde belirsizliğe tepkisi, karar almadan tümüyle kaçınmak olarak ortaya çıkmaktadır. Kısaca belirsizlik, bireyin düşüncelerini hılı ve tutarlı olarak organize etmesini engellediğinden kişiler erteleme, karar verme sorumluluğunu başkasına verme ya da bir karar almayı tamamen erteleme eğiliminde olabilmektedirler (14). Üniversite öğrencilerinde yapılan bir çalışmada öğrencilerin \%89'unun pandeminin yarattığı belirsizlik nedeniyle motive olmada zorluk yaşadığ gösterilmektedir (7). Öğrencinin motivasyonu eğitimde önemli psikolojik kavramlardan biridir. Motivasyon, öğrencinin aktif katılım ve öğrenme sürecine katkı sağlar (15). Dolayısıyla eğitimde amaç, içerik, süreç, yöntem, ortam gibi konular öğrencilerin motivasyonlarını büyük ölçüde etkileyeceği düşünülmektedir (16). Çaresizlik ve belirsizlik duyguları düşük performans için mazeret olmakta ve ruh hali değişimini olumsuz etkilemektedir. Yapılan literatür araştırması sonucunda bu konuya ilişkin sınırlı sayıda çalışmaya rastlanmaktadır. Bu çalışmada COVID-19 pandemisinin halen ne kadar süreceği ve tedavisi hakkındaki bilinmezlik eğitimin aksamasına ve dolayısıyla birer sağlık hizmeti sunucusu olacak meslek yüksekokulu öğrencilerinde bu belirsizliğin etkisini belirlemek amaçlanmıştır.

\section{GEREÇ VE YÖNTEMLER}

\section{Araştırmanın Tipi}

Tanımlayıcı tipte olan bir araştırmadır.

\section{Araştırmanın Evren ve Örneklemi}

Araştırma Karadeniz bölgesinde bulunan iki devlet üniversitesinin meslek yüksekokulunda öğrenim gören sağlık bölümü (diyaliz, ilk ve acil yardım, fizyoterapi, yaşlı bakımı, çocuk gelişimi, tıbbi laboratuvar teknikleri, tıbbi dokümantasyon ve sekreterlik) 2. sınıf öğrencileri öğrencilerinde Mayıs 2020'de yapıldı. Araştırmanın evrenini bu üniversitelerde okuyan 1180 öğrenci oluşturdu ve örneklem seçimine gidilmeyerek evrenin tamamına ulaşılması hedeflendi. Ancak pandemi dolayısıyla okulların eğitime ara vermesi, interneti olmayan öğrencilerin olması, araştırmaya katılmayı istememe nedenleriyle 373 öğrenci kapsam dışı bırakıldı. Araştırma $807 \quad(\% 68,4) \quad$ katılımcı öğrenci ile gerçekleştirildi.

\section{Veri Toplama Araçları}

Araştırmada veri toplama araçları olarak; literatür taraması sonucu araştırmacılar tarafından oluşturulan Birey Tanıtım Formu, Belirsizliğe Tahammülsüzlük Ölçeği kullanıldı.

\section{Birey Tanıtım Formu}

Birey tanıtım formu literatür taraması sonucu araştırmacılar tarafından oluşturulan 15 soruluk anketin ilk 9 soru öğrencilerin sosyo-demografik özelliklerine ilişkin, kalan 6 soru ise COVID-19 ile ilgilidir. COVID19'la alakalı sorular hastalığın öğrenciler üzerindeki ruh hali değişimine etkisini araştırmak için literatürden yararlanılarak oluşturulan sorular içermektedir $(17,18)$.

Belirsizliğe Tahammülsüzlük Ölçeği (BTÖ)

Freeston (19) tarafından 2005 yılında geliştirilen 27 maddelik bu ölçek bilişsel, duygusal ve davranışsal reaksiyonlara verilen belirsizlik durumunu değerlendirmek için geliştirilmiştir. Değerlendirmeyi 5 Likert ölçekte yapılmıştır (1: Beni hiç tanımlamıyor, 2: Beni tanımlıyor, 3: Kısmen tanımlıyor, 4: Tanımliyor, 5: Beni tam olarak tanımlıyor). Ölçeğin Türk versiyonunu 2007 yılında Sevda Sarı tarafından yapılmıştır. Ön ve ana 
çalışmalarda güvenilirlik ve geçerlilik analizi için üniversite öğrencileri ile kullanılmıştır. BTÖ’nün Türkçe formunun Cronbach alfa değeri 0,93 olduğu görülmüştür. Ölçekten alınan puanlar yükseldikçe belirsizliğe tahammülsüzlük artmaktadır. BTÖ, dört alt boyuttan oluşmaktadır (20).

1) Belirsizlik üzücü ve stres vericidir.

2) Belirsizlik eyleme geçmeyi engeller.

3) Belirsiz olaylar olumsuzdur ve kaçınılması gerekir.

4) Belirsizlik adil değildir (20).

Veri Toplama Yöntemi

Veriler araştırmanın yapıldığı üniversitelerden araştırmaya katılmayı kabul eden öğrenciler ile internet ve mobil cihaz uygulaması kullanılarak araştırmacılar tarafından uygulanmıştır. Veri toplama işlemi bir katılımcı için yaklaşık 5-10 dakika sürdü.

\section{Araştırmanın Etik Yönü}

Araştırmanın uygulanabilmesi için Gümüşhane Üniversitesi Etik Kurulu'ndan etik kurul izni (tarih:05.05.2020 ve say1:2020/5) ve üniversitelerden kurum izinleri alındı. Araştırmaya katılan öğrencilere çalışmanın amacı ve önemi açıklandı. Katılımın gönüllülük esasına göre olduğu belirtildikten sonra, araştırmaya katılmada istekli olan öğrencilerin aydınlatılmış onam ilkesi dikkate alınarak çalışmaya dahil edilmiştir. Araştırmaya başlamadan önce Belirsizliğe Tahammülsüzlük Ölçeğini kullanabilmek için sorumlu yazardan mail yoluyla yazılı izinler alınmıştır.

\section{Araştırmanın Sınırlılıkları}

$\mathrm{Bu}$ araştırmada örneklemin üniversitelerin önlisans programlarında okuyan tüm öğrencileri temsil etmeyip, öğrencinin araştırmanın yürütüleceği üniversiteye kayıtlı olması ve eğitimine devam ediyor olması araştırmanın sinırlılıkları arasındadır.

\section{İstatistiksel Analiz}

Verilerin değerlendirilmesinde SPPS 23,0 istatistik paket programı kullanıldı. Değerlendirme sonuçlarının tanımlayıcı istatistikleri; kategorik değişkenler için sayı ve yüzde, sayısal değişkenler için ortalama, standart sapma olarak verildi. Grupların normal dağılıma uygunluğu One-Sample Kolmogorov Smirnov testi ile belirlendi. Bağımsız iki grup arasında sayısal değişkenlerin karşılaştırmaları Student-t test ile değerlendirildi. Bağımsız gruplarda kategorik değişkenlerin oranları arasındaki farkların analizinde ise ki-kare testi kullanıldı. İstatistiksel alfa anlamlılık seviyesi 0,05 olarak kabul edildi.

\section{BULGULAR}

Araştırmamız 807 öğrenci ile gerçekleştirildi. Katılımciların \%76,6'si (n=618) kadın, \%98,4'ü (n=794) bekardır. Öğrencilerin \%55,6'sı $(n=449)$ örgün eğitim, \%44,4’ü (n=358) ikinci öğretimdedir. Katılımcıların yaklaşık yarısı $(\% 47)$ il merkezinde yaşamakta olup büyük çoğunluğunun $(\% 70,8)$ gelir durumu orta düzeydedir. Öğrencilerin pandemi sırasındaki ruh hali değişimi sorguladığında yüksek bir oranda $(\% 53,7)$ kötüye gittiği ve yine yüksek bir oranda $(\% 63,2)$ psikososyal destek hizmeti aldığı bulunmuştur. Pandemi sırasında izolasyon önlemi alma durumu \%95,2 ( $\mathrm{n}=768)$ iken; karantina önlemi alma durumu \%18,3 (n=148) olarak saptanmıştır (Tablo 1).
Tablo 1. Katılımcıların tanıtıcı özellikleri

Özellikler n

$\%$

\begin{tabular}{lcc}
\hline Cinsiyet & & \\
Kadın & 618 & 76,6 \\
Erkek & 189 & 23,4 \\
Gelir Durumu & 177 & \\
İyi & 571 & 21,9 \\
Orta & 59 & 70,8 \\
Kötü & & 7,3 \\
Medeni Durum & 13 & 1,6 \\
Evli & 794 & 98,4 \\
Bekar &
\end{tabular}

Öğrenim Durumu

Örgün Eğitim $\quad 449 \quad 55,6$

İkinci Öğretim $\quad 358 \quad 44,4$

Yaşanılan Yer

İl $\quad 379 \quad 47,0$

İlçe $\quad 244 \quad 30,2$

$\begin{array}{lll}\text { Köy } & 184 & 22,8\end{array}$

Pandemi Sırasındaki Ruh Hali Değişim Durumu

$\begin{array}{lll}\text { İyi } & 85 & 10,5\end{array}$

$\begin{array}{lll}\text { Neredeyse değişmedi } \quad 181 & 22,4\end{array}$

$\begin{array}{lll}\text { Kötü } & 433 & 53,7\end{array}$

$\begin{array}{lcc}\text { Çok daha kötüye gidiyor } \quad 108 & 13,4\end{array}$

Pandemi Sırasında İzolasyon Önlemi Alma Durumu

Evet $768 \quad 95,2$

$\begin{array}{lll}\text { Hayır } & 39 & 4,8\end{array}$

Pandemi Sırasında Karantina Önlemi Alma Durumu

$\begin{array}{lll}\text { Evet } & 148 & 18,3\end{array}$

$\begin{array}{lll}\text { Hayır } & 659 & 81,7\end{array}$

Pandemi Surasında Psikososyal Destek Hizmeti Alma Durumu* $\begin{array}{lll}\text { Evet** }^{* *} & 510 & 63,2\end{array}$

$\begin{array}{lll}\text { Medya } & 327 & 40,5\end{array}$

$\begin{array}{lll}\text { Psikolojik materyaller } & 133 & 16,5\end{array}$

Danışmanlık veya $\quad 81 \quad 10,0$

psikoterapi

Diğer

0,4

$297 \quad 36,8$ 
**Medya yoluyla: TV, radyo, telefon, sosyal medya yoluyla alınan hizmet; psikolojik materyaller: Covid-19 ile ilgili broșür ve eğitim kitapçıları; danıșmanlık veya psikoterapi: çevrimiçi danışmanlık veya psikoterapi; diğer: çevresinden alınan sosyal destek

Öğrencilerin belirsizliğe tahammülsüzlük ölçeğinden alınan toplam puan ve alt boyut puanları gösterilmiştir (Tablo 2).

Tablo 2. Belirsizliğe tahammülsüzlük ölçeği ve alt boyutlarından alınan puan değerleri

\begin{tabular}{lll}
\hline Alt Boyutlar & Ort \pm SS* & $\begin{array}{l}\text { Min- } \\
\text { Maks** }\end{array}$ \\
\hline Belirsizlik stres verici ve üzücüdür & $30,5 \pm 7,9$ & $9-45$ \\
\hline $\begin{array}{l}\text { Belirsizlik ile ilgili olumsuz benlik } \\
\text { değerlendirmeler }\end{array}$ & $22,5 \pm 6,3$ & $8-40$ \\
\hline Geleceği bilememek rahatsız edicidir & $13,3 \pm 3,8$ & $4-20$ \\
\hline Belirsizlik eyleme geçmemi engelliyor & $16,6 \pm 4,5$ & $5-25$ \\
\hline Toplam & $83,7 \pm 19,9$ & $26-129$ \\
\hline *Ort: Ortalama, SS: standart sapma, **Min: Minimum, Maks: Maksimum
\end{tabular}

Araştırmaya katılanların sosyal izolasyon sırasındaki duygu durumları incelendiğinde, öğrenciler tarafından en yüksek oran $\% 41,4 \quad(n=334)$ ile sikıntılı cevab1 verilmiştir. $\mathrm{Bu}$ duygu durumunu sırasiyla korku, mutsuzluk ve çaresizlik takip etmiştir (Şekil 1).

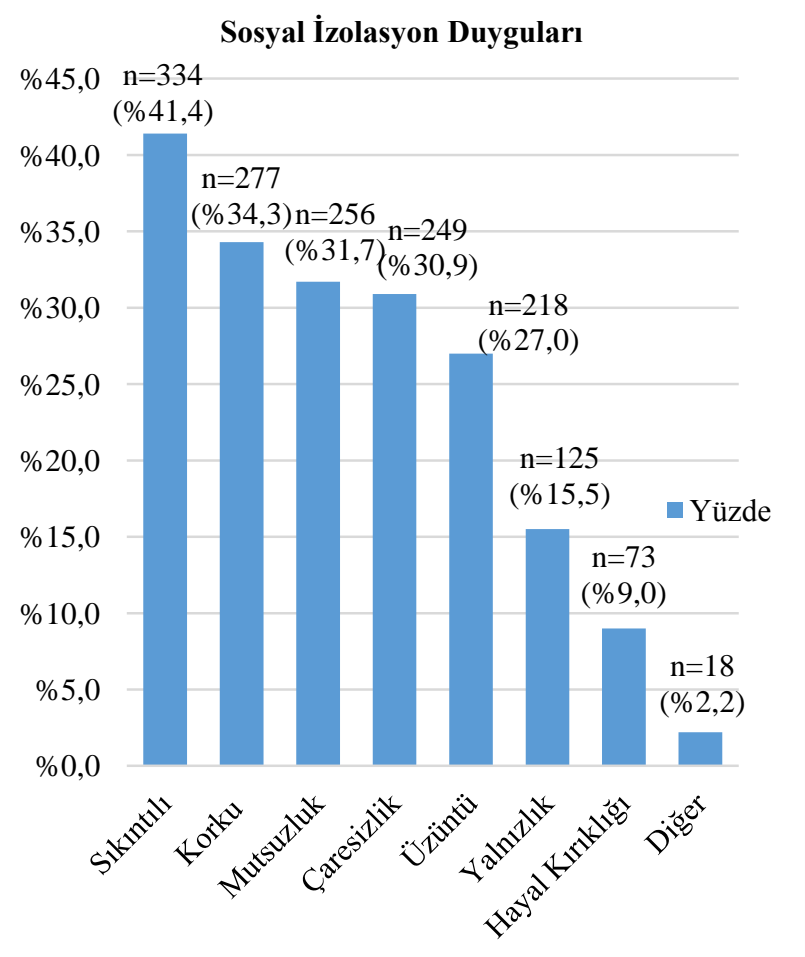

Katılımcılar birden fazla seçenek işaretlemişlerdir.

Şekil 1. Katılımcıların sosyal izolasyon konusundaki duygularının dağılımları

Araştırmaya katılanların karantinadaki duygu durumları incelendiğinde, öğrenciler tarafından en yüksek oran \%24 $(\mathrm{n}=194)$ ile korku cevabı verilmiştir. Bu duygu durumunu sırasıyla üzüntü, mutsuzluk ve çaresizlik takip etmiştir (Şekil 2).

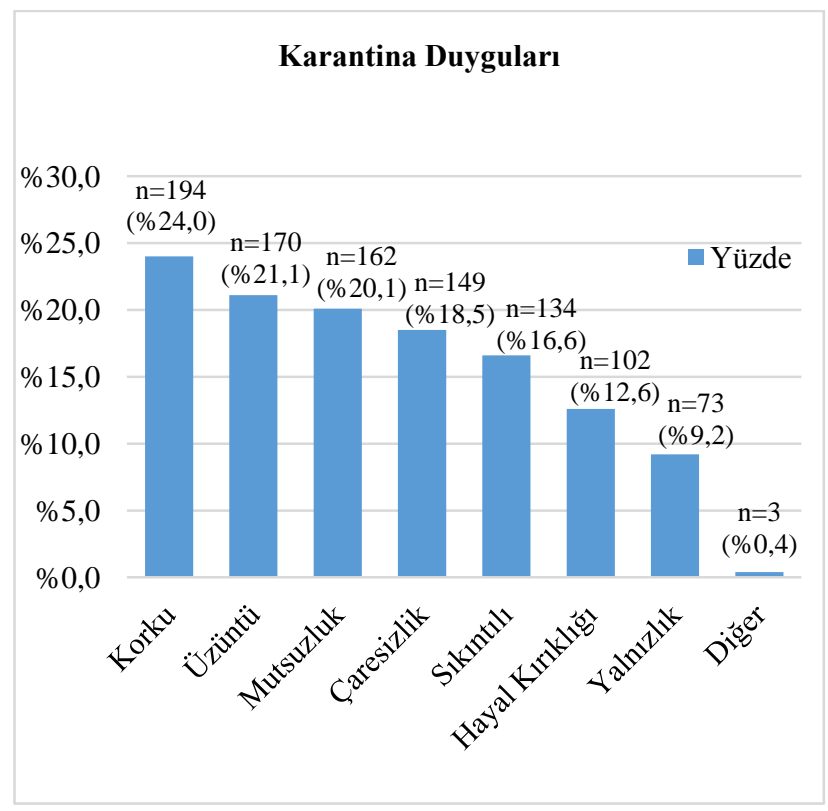

Katılımcılar birden fazla seçenek işaretlemişlerdir

Şekil 2. Katılımcıların karantina konusundaki duygularının dağılımları

Öğrencilerin pandemi sürecindeki ruh hali değişimini kötü olarak niteleyenlerin \%65,6’sı $(n=355)$ psikososyal destek hizmeti almışken; ruh hali değişimini iyi olarak belirtenlerin \%58,3'ü $(n=155)$ psikososyal destek hizmeti almıştır. Bu iki yüzde arasındaki fark istatistiksel olarak önemlidir $(\mathrm{p}=0,042)$ (Tablo 3).

Tablo 3. Öğrencilerin pandemi sürecindeki ruh hali değişimi ile aldığı psikososyal destek hizmeti arasındaki oranların karşılaştırılması

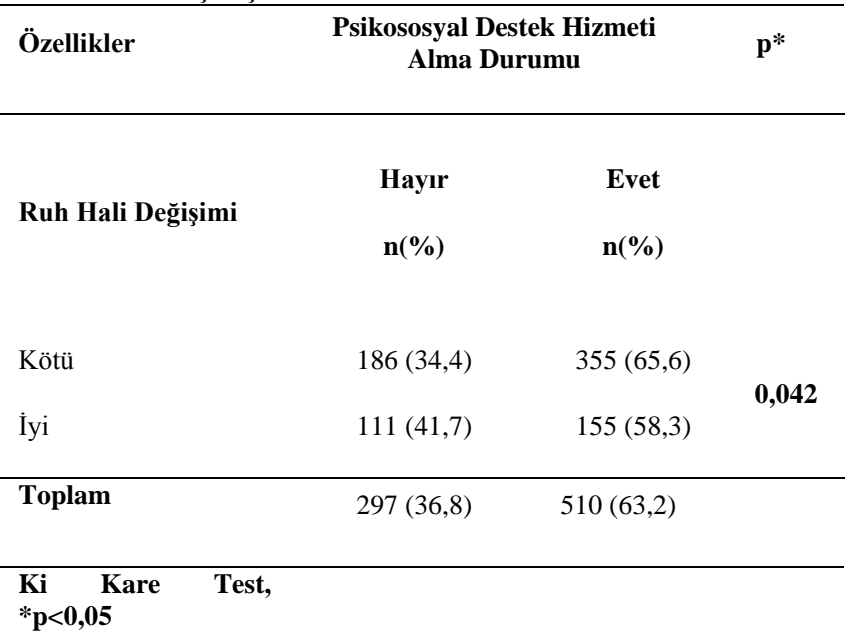

Öğrencilerin COVID-19 hastalığına ilişkin verileri ile Belirsizliğe Tahammülsüzlük Ölçeğinden alınan puanlar karşılaştırıldığında, ruh hali değişimini kötü olarak niteleyenlerde, karantinaya alınanlarda, psikososyal destek hizmeti alanlarda ölçek puanları istatistiksel olarak yüksek düzeyde bulunmuştur $(\mathrm{p}<0,05)$. Sosyal izolasyon önlemleri alma durumunda istatistiksel olarak önemli fark saptanmamıştır (Tablo 4). 
Tablo 4. Öğrencilerin COVID-19 hastalığına ilişkin verileri ile belirsizliğe tahammülsüzlük ölçeğine ait puan ortalamalarının dağılımı

Belirsizliğe Tahammülsüzlük Ölçeği

\begin{tabular}{|c|c|c|c|}
\hline & $\mathbf{n}$ & Ort \pm SS* & $\mathbf{p}^{\text {*** }}$ \\
\hline \multicolumn{4}{|l|}{ Ruh Hali Değişimi } \\
\hline Daha Kötü & 541 & $88,2 \pm 18,6$ & $<0,001$ \\
\hline Daha İyi - Değişmedi & 266 & $74,6 \pm 19,3$ & \\
\hline \multicolumn{4}{|c|}{ Sosyal İzolasyon Önlemleri Alma } \\
\hline Hayır & 39 & $89,7 \pm 19,6$ & 0,084 \\
\hline Evet & 768 & $83,4 \pm 19,9$ & \\
\hline \multicolumn{4}{|c|}{ Karantina Altına Alınma } \\
\hline Hayır & 659 & $82,8 \pm 19,8$ & 0,003 \\
\hline Evet & 148 & $87,9 \pm 19,9$ & \\
\hline
\end{tabular}

\begin{tabular}{lccc}
\hline Psikososyal Destek Hizmeti Alma Durumu & & \\
& & & \\
\hline Hayır & 297 & $80,7 \pm 19,4$ & $<\mathbf{0 , 0 0 1}$ \\
& & & \\
Evet & 510 & $85,5 \pm 20,0$ &
\end{tabular}

Student t test, *Ort: Ortalama, SS: standart sapma, ${ }^{* *} \mathbf{p}<\mathbf{0 , 0 5}$

\section{TARTISSMA}

Birleşmiş Milletler Eğitim, Bilim ve Kültür Örgütü pandemi nedeniyle eğitim kurumlarının kapatılmasının dünyadaki 114 ülkede 890 milyon öğrenciyi etkilediğini belirtmektedir (21). Uzaktan çevrimiçi öğretim bazı öğrenciler için yeni bir rutin ve önemli zorluklar sunmaktadır. Birçok ülkede sosyal eşitsizlik göz önünde bulundurulduğunda, tüm öğrencilerin bu tür eğitime erişimi yoktur. Bu sebeple milyonlarca öğrenci eğitimde aksama yaşamaktadır. Dünyadaki birçok üniversite, ögrrencilerde ve akademisyenlerde kaygı ve belirsizlik yaratan koronavirüs krizinin psikolojik açıdan yıkıcı etkileri olduğunu belirtmiştir $(10,22)$. Belirsizlik durumunda karar verme yetileri en aza inen bireyler bazı ruhsal sorunlar yaşayabilir. Pandemiden dolayı oluşan bu belirsizlik süreci öğrencilerin akademik çalışmalarını olumsuz etkileyebilir ancak gelecekte bazı beklentilerinin gerçekleşeceğine inanması ve bu beklentilere ulaşmak için çalışmaya motive olmaları bu durumu tersine çevirebilir.

COVID-19 hastalarının, tedavi ve bakımıyla doğrudan ilgilenen sağlık personelleri de fizyolojik ve psikolojik açıdan risk altındadır (23). COVID-19'a karşı mücadelede gelişmiş sağlık sistemlerine sahip olan ülkeler bile insan kaynakları eksikliği ve ekipman yetersizliği ile karşı karşıyadır. Bu nedenle, insan kaynaklarını en üst düzeye çıkarmak başarının anahtarlarından biridir. Sadece sağlık çalışanları değil ayrıca tıp, hemşirelik ve diğer sağlık çalışanı öğrencileri salgının önlenmesinin her aşamasına katkıda bulunabilir (24). Sağlık programlarında öğrenim gören öğrencilerin halk sağlığı acil durumlarında duygularını etkili ve uygun bir şekilde düzenlemeye ve kriz olaylarından kaynaklanan kayıpları önlemeye yönelik rehberlik etme yöntemleri, üniversiteler için acil bir sorun haline gelmiştir (10). Dolayısıyla üniversitelerdeki müfredat öğrencilerin eğitim ihtiyaçlarını her açıdan karşılayacak şekilde düzenlenmelidir. Bu düzenleme ile mezun olan öğrenciler salgın durumlarının yarattığı kaygı, korku, tedirginlik ve ciddi endişe gibi olumsuz duyguları daha iyi yönetebilen eylem ve davranışları sağlayabilecek ve çalışmaya daha istekli olacaklardır $(25,26)$.

Araştırmaya katılan öğrencilerin çoğunluğu kadın, bekar, gelir düzeyi orta ve il merkezi yerleşimlidir. Ayrıca öğrencilerin çoğunluğunun pandemi döneminde izolasyon önlemi aldığ 1 , ruh hali değişiminin kötüye gittiği ve yine yüksek bir oranda psikososyal destek hizmeti aldığı belirlenmiştir.

Araştırmada öğrencilerin COVID-19'a ilişkin verileri ile belirsizliğe tahammülsüzlük düzeyinden alınan puanlar karşılaştırıldığında karantinaya alınan, ruh hali değişimini kötü olarak niteleyen ve psikososyal destek hizmeti alanlarda ölçek puanları yüksek bulunmuştur. Pandeminin birçok öğrencide okulların kapanması nedeniyle rutin kaybı ve kısıtlı sosyal bağlantıları sebebiyle zihinsel sağlık koşullarını kötüleştirdiği belirtilmiştir (10, 27-33). Yapılan çalışmalar, araştırma sonucumuzu desteklemekle birlikte bu bilgiler 1şı̆̆ında pandeminin, uzun bekleme süreleri ve belirsizlik oluşturmasından dolayı öğrencilerin zihinsel sağlık sorunlarını daha da kötüleștirebilmektedir. Araştırmamızda belirsizliğe tahammülsüzlük alt boyutları ve ölçeğin toplam puanı ortalamanın üzerindedir. Literatürde farklı zaman dilimi ve örneklem grubunda yapılan bir çalışmada araştırmamızı destekler niteliktedir (34). Yapılan bir çalışmada belirsizliğe yüksek seviyedeki tahammülsüzlüğün, psikolojik stresle ilişkili olduğu ve adaptif bir tepki olmadığı belirtilmiştir. Belirsizliğe tahammülsüz bireylerin içinde bulunduğu durumun önemi olmaksızın, olaylar hakkındaki bilinmezlikten dolayı endişe, stres ve anksiyeteye daha yatkın oldukları öne sürülmüştür (35-37). Bu sonuçlar araştırmamızı destekler niteliktedir. Dolayısıyla belirsizliğe tahammülsüz bireylerin, uzun süreli öngörülemez durumlara maruz kaldıklarında fiziksel ve psikolojik sağlıklarında bozulma olabilir.

Araştırmamızda öğrencilerin büyük çoğunluğu ruhsal açıdan kendilerini daha iyi hissedebilmek adına medya, kitap, broşür veya çevrimiçi psikoterapi gibi yöntemlere başvurmuşlardır. Coşkun (38) öğrencilerde yaptığı tez çalışmasında psikolojik yardım almış olanların belirsizliğe tahammülsüzlük puan ortalamalarının psikolojik yardım almayanlara göre daha yüksek olduğunu saptamıştır. Pandemi öğrencilerin mezuniyetlerinin gecikmesi ve dolayısıyla gelecekteki istihdamları üzerindeki belirsizlik endişelerini arttırabilir. Evden uzakta kalan öğrenciler sadece sağlıkları, güvenlikleri ve eğitimleri konusunda endişelenmekle kalmaz, aynı zamanda ailelerinin refahı için de çok sayıda endişeleri olabilir. Literatürde pandemi kapsamında farklı 
örneklem grubunda yapılan araştırmada, Kang ve arkadaşları (18) hemşirelerin psikososyal destek hizmet kaynaklarından sırasıyla en fazla medya, psikolojik materyaller ve çevrimiçi psikolojik danışmanlık hizmeti aldığını saptamıştır. Çin'de bir hastanede COVID-19 salgınında kişilerin acil psikolojik sorunlarıyla daha iyi başa çıkabilmesi için internet teknolojisi kullanarak yeni bir psikolojik kriz müdahale modeli geliştirilmiştir. Çevrimiçi psikolojik müdahalede doktorları, psikiyatrları, psikologları ve sosyal hizmet uzmanlarını internet platformlarına entegre ederek hastalara, ailelerine ve sağlık personeline psikososyal müdahale hizmetleri verilmiştir (39). Aynı zamanda ülkemizde de COVID-19 ile mücadele sürecinde telefonla psikososyal destek hizmeti verilmektedir (40). Yapılan diğer çalışmalarda da salgın döneminde çevrimiçi psikolojik müdahalelerin gerekli önlemler arasında olduğu belirtilmiştir (41-43). $\mathrm{Bu}$ sonuçlar araştırmamızı destekler niteliktedir. $\mathrm{Bu}$ bağlamda, öğrencilerin medya aracılığıyla aldığı psikososyal destek hizmetlerine daha kolay ve ucuz yolla ulaşabildiği düşünülmektedir. Psikososyal destek hizmetleri, zihinsel sağlık sorunlarını ve fiziksel rahatsızlığ 1 hafifletmeye ve belirsizliğe tahammülsüzlük düzeyinin de olumlu yönde artmasına katkıda bulunabilir. Dolayısıyla psikososyal destek hizmeti almış olan öğrenciler bu zorlu şartlara uyum sağlayabilir, gelecek beklentilerini planlayabilir ve geliştirebilir.

Karantina, genellikle maruz kalanlar için hoş olmayan bir deneyimdir (44). Sevdiklerinden ayrılma, özgürlük kaybı, hastalık durumu üzerindeki belirsizlik ve can sıkıntısı zaman zaman dramatik etkiler yaratabilir (17). Araştırmamızda kendisi, ailesi veya yakın arkadaşlarından herhangi biri karantinaya alınan öğrencilerin belirsizliğe tahammülsüzlük düzeyi yüksek olarak belirlenmiştir. Literatürde pandemi kapsamında farklı örneklem grubunda yapılan ve araştırmamızı destekleyen çeşitli çalışmalarda, karantinaya alınan kişilerde, psikolojik ve duygusal güçlükler yaşandığ belirtilmiştir (45-51). Lei ve arkadaşları (51) yaptığ çalışmada karantinaya alınan bireylerde anksiyete ve depresyon gözlenmiştir. Okulların kapanması ve uzaktan eğitime geçilmesi nedeniyle evlerine dönmek zorunda kalan öğrenciler COVID-19 kapsamında alınan önlemlerden dolayı 14 günlük karantinadan sonra ailelerine kavuşabilmektedir. Dolayısıyla karantina öğrencilerde belirsizlik, güvensizlik, korku, kayıp duygusu ve ruh hali değişimlerine katkı sağlayabilir.

\section{SONUÇ}

COVID-19 dahil endemi ve pandemiler insanlık için bir sınav ve öğretme özelliğine sahip olaylardır. Bu durum sadece yöneticiler, bilim dünyası, eğitmenler ve sağlık sistemi için değil tüm bireyleri kapsamaktadır. Belirsizliklerden dolayı COVID-19 salgını kafa karışıklığı ve eğitimde aksamalara sebep olmuştur. Günümüzde üniversite öğrencileri, bir yandan akademik başarılara odaklanırken diğer yandan da toplumu her açıdan etkileyen COVID-19 salgınıla mücadele etmektedirler. Gelecekte bu mücadelenin ön saflarında yer alacak olan lisans ve ön lisans sağlık programlarında öğrenim gören öğrencilerde mesleğe ve geleceğe yönelik beklentilerde belirsizlik oluşabilir. Dolayısıyla pandemi sürecinde belirsizliğe tahammülsüzlük önemli bir kavram olarak karşımıza çıkmaktadır. Çünkü belirsizliğe dair pozitif düşünce ve beklentiler geliştiren öğrenci, akademik başarılarına odaklanabilir ve gelecek beklentilerine olan inancını arttırabilir. Araştırmamızın sonuçları, pandemi sürecinde ruh hali değişiminin etkilenmemesi veya en az etkiyle geçirilebilmesi için bazı psikososyal müdahalelerin uygulanmasına destek sağlayabilir.

Psikososyal destekli eğitimde kriz ve stres yönetimi, baş etme yöntemleri ve sosyal destek kaynaklarının güçlendirilmesi yönünde çalışmalar önem arz etmektedir. Dolayısıyla standart sağlık eğitiminin bir parçası olarak psikososyal destekli eğitimin etkisi ve güvenliği hakkında geleceğin sağlık profesyonelleri olacak öğrencilerimizin bilgilendirilmesi ve desteklenmesi önerilmektedir.

Yazar Katkıları: Fikir/Kavram B.Ö., A.K., Tasarım B.Ö., A.K., E.Ö., Veri Toplama ve/veya İşleme B.Ö., A.K., S.K., Analiz ve/veya Yorum B.Ö., A.K., S.K., Literatür Taraması B.Ö., A.K., Makale Yazımı B.Ö., A.K., Eleştirel İnceleme B.Ö., A.K., E.Ö.

\section{KAYNAKLAR}

1. Centers for Disease Control and Prevention [Internet].Coronavirus Disease 2019 (COVID-19) How to Protect Yourself 2020 [Updated: 2021 March 8; Cited: 2020 April 4]. Available from: https://www.cdc.gov/coronavirus/2019ncov/prepare/prevention.html.

2. World Health Organization [Internet]. Coronavirus disease (COVID-19) advice for the public 2021 [Updated: 2021 March 26; Cited: 2020 May 12]. Available from: https://www.who.int/emergencies/diseases/novelcoronavirus-2019/advice-for-public.

3. European Centre for Disease Prevention and Control [Internet]. Novel coronavirus disease 2019 (COVID19) pandemic: increased transmission in the EU/EEA and the UK - sixth up date [Updated: 2021 March 26; Cited 2020 April 15]. Available from: https://www.ecdc.europa.eu/sites/default/files/docume nts/RRA-sixth-update-Outbreak-ofnovel-coronavirusdisease-2019-COVID-19.

4. Wang G, Zhang Y, Zhao J, Zhang J, Jiang F. Mitigate the effects of home confinement on children during the COVID-19 outbreak. The Lancet. 2020;395(10228):945-947.

5. Wang G, Zhang J, Lam SP, Li SX, Jiang Y, Sun W, et al. Ten-year secular trends in sleep/wake patterns in Shanghai and Hong Kong school-aged children: a tale of two cities. Journal of Clinical Sleep Medicine. 2019;15(10):1495-1502.

6. Kaparounaki CK, Patsali ME, Mousa D-PV, Papadopoulou EV, Papadopoulou KK, Fountoulakis KN. University students' mental health amidst the COVID-19 quarantine in Greece. Psychiatry Research. 2020;290:113111.

7. Son C, Hegde S, Smith A, Wang X, Sasangohar F. Effects of COVID-19 on college students' mental health in the United States: Interview survey study. Journal of Medical Internet Research. 2020;22(9):e21279.

8. Cellini N, Canale N, Mioni G, Costa S. Changes in sleep pattern, sense of time and digital media use 
during COVID-19 lockdown in Italy. Journal of Sleep Research. 2020; 29(4): e13074.

9. Marelli S, Castelnuovo A, Somma A, Castronovo V, Mombelli S, Bottoni D, et al. Impact of COVID-19 lockdown on sleep quality in university students and administration staff. Journal of Neurology. 2021; 268(1): 8-15.

10. Cao W, Fang Z, Hou G, Han M, Xu X, Dong J, et al. The psychological impact of the COVID-19 epidemic on college students in China. Psychiatry Research. 2020; 287: 112934.

11. Tull MT, Barbano AC, Scamaldo KM, Richmond JR, Edmonds KA, Rose JP, et al. The prospective influence of COVID-19 affective risk assessments and intolerance of uncertainty on later dimensions of health anxiety. Journal of Anxiety Disorders. 2020; 75: 102290.

12. Carleton RN. The intolerance of uncertainty construct in the context of anxiety disorders: Theoretical and practical perspectives. Expert Review of Neurotherapeutics. 2012; 12(8): 937-47.

13. Boelen PA, Carleton RN. Intolerance of uncertainty, hypochondriacal concerns, obsessive-compulsive symptoms, and worry. The Journal of Nervous and Mental Disease. 2012;200(3):208-213.

14. Deschenes SS, Dugas MJ, Radomsky AS, Buhr K. Experimental manipulation of beliefs about uncertainty: Effects on interpretive processing and access to threat schemata. Journal of Experimental Psychopathology. 2010; 1(1): 52-70.

15. Kara A. İlköğretim birinci kademede eğitimde motivasyon ölçeğinin Türkçe'ye uyarlanması. Ege Eğitim Dergisi. 2008; 9(2): 57-78.

16. Şişman M. Eğitim bilimine giriş. Pegem Atıf İndeksi. 2017: 1-351.

17. Brooks SK, Webster RK, Smith LE, Woodland L, Wessely S, Greenberg N, et al. The psychological impact of quarantine and how to reduce it: rapid review of the evidence. The Lancet. 2020; 395(10227): 912-20.

18. Kang L, Ma S, Chen M, Yang J, Wang Y, Li R, et al. Impact on mental health and perceptions of psychological care among medical and nursing staff in Wuhan during the 2019 novel coronavirus disease outbreak: A cross-sectional study. Brain, Behavior, and Immunity. 2020; 87: 11-7.

19. Freeston MH, Rhéaume J, Letarte H, Dugas MJ, Ladouceur R. Why do people worry? Personality and Individual Differences. 1994; 17(6): 791-802.

20. Sarı S, Dağ İ. Belirsizliğe tahammülsüzlük ölçeği, endişe ile ilgili olumlu inançlar ölçeği ve endişenin sonuçları ölçeğinin Türkçeye uyarlanması, geçerliliği ve güvenirliği. Anadolu Psikiyatri Derg. 2009; 10(4): 261-70.

21. UNESCO [Internet]. COVID-19 educational disruption and response [updated 2020 March 24; Cited: 2020 June 8]. Available from: https://en.unesco.org/news/covid-19-educationaldisruption-and-response.

22. de Oliveira Araújo FJ, de Lima LSA, Cidade PIM, Nobre CB, Neto MLR. Impact of Sars-Cov-2 and its reverberation in global higher education and mental health. Psychiatry Research. 2020; 288: 112977.
23. Lai J, Ma S, Wang Y, Cai Z, Hu J, Wei N, et al. Factors associated with mental health outcomes among health care workers exposed to coronavirus disease 2019. JAMA Network Open. 2020; 3(3): e203976.

24. Tran BX, Dang AK, Thai PK, Le HT, Le XTT, Do TTT, et al. Coverage of health information by different sources in communities: implication for COVID-19 epidemic response. International Journal of Environmental Research and Public Health. 2020; 17(10): 3577-89.

25. London M. Toward a theory of career motivation. Academy of Management Review. 1983; 8(4): 620630.

26. Collado-Boira EJ, Ruiz-Palomino E, Salas-Media P, Folch-Ayora A, Muriach M, Baliño P. "The COVID19 outbreak"-An empirical phenomenological study on perceptions and psychosocial considerations surrounding the immediate incorporation of final-year Spanish nursing and medical students into the health system. Nurse Education Today. 2020; 92: 104504.

27. Agnew M, Poole H, Khan A. Fall break fallout: Exploring student perceptions of the impact of an autumn break on stress. Student Success. 2019;10(3):45-54.

28. Youngminds [Internet]. Coronavirus: Impact on young people with mental health needs. [Updated: 2020 March; Cited: 2020 May 10]. Available from: https://youngminds.org.uk/media/3708/coronavirusreport.

29. Franchi T. The impact of the Covid- 19 pandemic on current anatomy education and future careers: A student's perspective. Anatomical Sciences Education. 2020; 13(3): 312-5.

30. Chang J, Yuan Y, Wang D. Mental health status and its influencing factors among college students during the epidemic of COVID-19. Nan fang yi ke da xue $\mathrm{xue} \mathrm{bao}=$ Journal of Southern Medical University. 2020; 40(2): 171-6.

31. Sahu P. Closure of universities due to coronavirus disease 2019 (COVID-19): impact on education and mental health of students and academic staff. Cureus. 2020; 12(4): e7541.

32. Zhai Y, Du X. Addressing collegiate mental health amid COVID-19 pandemic. Psychiatry Research. 2020; 288: 113003.

33. Odriozola-González P, Planchuelo-Gómez Á, Irurtia MJ, de Luis-García R. Psychological effects of the COVID-19 outbreak and lockdown among students and workers of a Spanish university. Psychiatry Research. 2020; 290: 113108.

34. Uzunaslan İ. Geçici koruma statüsü altındaki Suriyeli kadınların belirsizlik toleranslarının bazı demografik değişkenler açısından incelenmesi [Yüksek Lisans Tezi]. Ankara: Ankara Üniversitesi Sağlık Bilimleri Enstitüsü, Sosyal Hizmet Anabilim Dalı; 2019.

35. Lally J, Cantillon P. Uncertainty and ambiguity and their association with psychological distress in medical students. Academic Psychiatry. 2014; 38(3): 339-44.

36. Boelen PA, Reijntjes A. Intolerance of uncertainty and social anxiety. Journal of Anxiety Disorders. 2009; 23(1): 130-5. 
37. Gentes EL, Ruscio AM. A meta-analysis of the relation of intolerance of uncertainty to symptoms of generalized anxiety disorder, major depressive disorder, and obsessive-compulsive disorder. Clinical Psychology Review. 2011; 31(6): 923-33.

38. Coşkun E. Duygusal zeka ve belirsizliğe tahammülsüzlüğün stresle başa çıkma tarzlarına etkisinin incelenmesi [Yüksek Lisans Tezi]. İstanbul: Fatih Sultan Mehmet Vakıf Üniversitesi Lisansüstü Eğitim Enstitüsü, Psikoloji Anabilim Dalı; 2019.

39. Zhang J, Wu W, Zhao X, Zhang W. Recommended psychological crisis intervention response to the 2019 novel coronavirus pneumonia outbreak in China: a model of West China Hospital. Precision Clinical Medicine. 2020; 3(1): 3-8.

40. Csgb.gov.tr [Internet]. T.C. Çalışma ve Sosyal Hizmetler Bakanlığı COVID-19 Nedeniyle Vatandaşlara Telefonla Psikososyal Destek Veriyor. [Erişim tarihi: 10.07.2020]. Erişim adresi: https://www.ailevecalisma.gov.tr/trtr/haberler/bakanligimiz-covid-19-nedeniylevatandaslara-telefonla-psikososyal-destek-veriyor/.

41. Xiang Y-T, Yang Y, Li W, Zhang L, Zhang Q, Cheung $\mathrm{T}$, et al. Timely mental health care for the 2019 novel coronavirus outbreak is urgently needed. The Lancet Psychiatry. 2020; 7(3): 228-9.

42. Yang Y, Li W, Zhang Q, Zhang L, Cheung T, Xiang Y-T. Mental health services for older adults in China during the COVID-19 outbreak. The Lancet Psychiatry. 2020; 7(4): e19.

43. Chatterjee K, Chauhan V. Epidemics, quarantine and mental health. Medical Journal, Armed Forces India. 2020; 76(2): 125-7.

44. Maunder R, Hunter J, Vincent L, Bennett J, Peladeau $\mathrm{N}$, Leszcz M, et al. The immediate psychological and occupational impact of the 2003 SARS outbreak in a teaching hospital. Cmaj. 2003; 168(10): 1245-51.

45. Bai Y, Lin C-C, Lin C-Y, Chen J-Y, Chue C-M, Chou P. Survey of stress reactions among health care workers involved with the SARS outbreak. Psychiatric Services. 2004; 55(9): 1055-7.

46. Sprang G, Silman M. Posttraumatic stress disorder in parents and youth after health-related disasters. Disaster Medicine and Public Health Preparedness. 2013; 7(1): 105-10.

47. Caleo G, Duncombe J, Jephcott F, Lokuge K, Mills C, Looijen E, et al. The factors affecting household transmission dynamics and community compliance with Ebola control measures: a mixed-methods study in a rural village in Sierra Leone. BMC Public Health. 2018; 18(1): 1-13.

48. Cava MA, Fay KE, Beanlands HJ, McCay EA, Wignall $R$. The experience of quarantine for individuals affected by SARS in Toronto. Public Health Nursing. 2005; 22(5): 398-406.

49. Reynolds DL, Garay J, Deamond S, Moran MK, Gold W, Styra R. Understanding, compliance and psychological impact of the SARS quarantine experience. Epidemiology \& Infection. 2008; 136(7): 997-1007.

50. Yoon M-K, Kim S-Y, Ko H-S, Lee M-S. System effectiveness of detection, brief intervention and refer to treatment for the people with post-traumatic emotional distress by MERS: a case report of community-based proactive intervention in South Korea. International Journal of Mental Health Systems. 2016; 10(1): 1-5.

51. Lei L, Huang X, Zhang S, Yang J, Yang L, Xu M. Comparison of prevalence and associated factors of anxiety and depression among people affected by versus people unaffected by quarantine during the COVID-19 epidemic in Southwestern China. Medical science monitor: International Medical Journal of Experimental and Clinical Research. 2020; 26: e924609-1- e924609-12. 